\title{
Marketing and sales alignment for improved effectiveness
}

\begin{abstract}
Laura Patterson
is a 25 plus year marketing and sales veteran having worked for both large public companies such as State Farm and Motorola and as well as start ups. In her career she has only worked for two types of people, engineers and accountants, both care deeply about data and numbers and so her passion for metrics was really based on career survival. In 1999 she co-founded VisionEdge Marketing (www.visionedgemarketing.com), a data-driven metrics-based strategic and product marketing company that specializes in improving marketing performance and helping organizations create a competitive advantage designed to attract, secure and retain profitable customers. Author of dozens of published marketing and branding articles and the books Gone Fishin' and Measure What Matters, Laura has served on several nonprofit boards, provided programming for professional organizations such as the ANA and BMA and has served as a guest lecturer at various universities, including the University of Texas at Austin, Stanford University, and Purdue University. Laura earned her BA from Truman State University and her Master's at the University of South Florida.
\end{abstract}

Keywords: marketing, sales cycles, sales funnel, customer buying pipeline, quotas, customers

Abstract Marketing and Sales are both responsible for generating revenue for the company. Regardless of various approaches taken by companies to address this issue, the lack of alignment and collaboration between marketing and sales persists. Both organizations need to change for the organization to succeed. This paper suggests how moving Marketing and Sales from a transactional approach to a customer-centric approach and using the customer buying process aligns the organizations and improves both organizations' effectiveness at growing the top line.

Journal of Digital Asset Management (2007) 3, 185-189. doi:10.1057/palgrave.dam.3650089

\section{INTRODUCTION}

Marketing and Sales are really two sides of the same coin. They are both responsible for generating revenue for the company. Revenue is a result of a straightforward equation $[\mathrm{Rev}=($ PipeOpp $\times$ Avg Deal $\times$ WinRate $) /$ CycleTime) $\times$ Sellers]: Opportunities in the pipeline multiplied by the average deal size multiplied by the win rate and then this product is divided by the sales cycle time. This result multiplied by all the sellers in your organization determines your revenue. Even a small increase in any of these variables can make a huge difference. The better marketing and sales are aligned, the more likely each of these factors can be improved thereby increasing the company's revenue. Yet the lack of alignment between Marketing and Sales inhibits many companies from achieving their revenue goals.

As a point of reference, some of the most recent research conducted by CSO Insights and IDC reveal four issues that are a result of this lack of alignment:
1. Longer sales cycles: Today's sales cycles are 25 per cent longer than they were a year ago.

2. Missed quotas: Only about 43 per cent of sales representatives (reps) made quota in 2006.

3. Productivity: Sales staff use up to 40 per cent of their time each week developing materials to support their sales efforts.

4. Sales efficiency: Fewer than 25 per cent of CMOs and 14 per cent of Senior Sales Executives are satisfied with their ability to optimize sales efficiency and effectiveness.

A CMO Study conducted by The Red Herring found that 42 per cent of the respondents gave marketing and sales alignment a nine or a ten (probably should include what the scale meant was 9 or 10 considered high or low and what was the max, etc) in terms of being one of the top crucial issues they need to address.

This issue of marketing and sales alignment is not new. Most marketing and sales people have been in organizations where Marketing has been 
known to accuse Sales of not following up on leads and refusing to track leads through the sales cycle, and Sales has been known to accuse Marketing of not providing viable qualified leads. This misalignment is often attributed to a variety of factors, such as different goals, different performance targets and metrics, different timelines and different psychologies. Market dynamics such as commoditization, internet growth, mobility and virtualization and changing business models only compound the problem.

Companies attempting to resolve the issue often approach the problem by trying to tighten the alignment of marketing activities within the sales cycle, improving coordination around lead generation and increasing sales force participation in the marketing process. Unfortunately, these attempts often fail. Regardless of various approaches taken by companies to address this issue, the lack of alignment and collaboration between marketing and sales persists. Both organizations need to change for the company to succeed.

This paper suggests two steps any company can take to improve marketing and sales alignment and ultimately marketing and sales effectiveness. The first step is to shift from a transactional focus to a customer focus. The second step is to build on customer focus by transforming the traditional sales funnel into a customer buying pipeline process that aligns customer acquisition efforts of both marketing and sales.

\section{FROM TRANSACTIONAL TO CUSTOMER CENTRICITY}

Achieving greater alignment begins with the marketing and the sales organizations deciding together which market segments offer the best opportunities and deserve the highest priorities. Today's buyers are more sophisticated and today's buying processes are more complex. The transactional approach of Marketing generating qualified leads that Sales then brings to a close is an outdated view. The transactional approach is what permits and even encourages Marketing and Sales to operate as independent, unrelated silos of business activities. This results in Sales immersing itself in the latest training, engaging in calling on customers and focusing on post-sale efforts; and Marketing focusing on implementing various campaigns and coordinating a variety of tactics.

Customer Centricity takes a different view that requires a company to look at opportunity from the perspective of the customer, what they want from you, what they expect from you and what they can count on from you. One way to develop customer centricity is to move away from a myopic selling perspective to a broader customer relationship lifecycle perspective. Taking a customer relationship lifecycle approach provides an avenue for alignment by focusing both the marketing and sales organizations on the same set of outcomes - creating, keeping and increasing the value of customers.

The customer relationship lifecycle begins the moment a customer appears on the radar screen, moves into the lead-sales funnel, emerges as a customer and engages in a variety of experiences that result in them becoming an advocate for your company. The customer relationship lifecycle provides insight into which customers provide the greatest lifetime value to your company.

The customer relationship lifecycle, in turn, enables the company to create a set of common metrics equally applicable to both sales and marketing organizations that will help ensure alignment. Customer relationship management metrics include buying-related metrics such as recency, frequency and quantity; cost-related metrics such as gross amount of money spent on acquiring and retaining the customer through marketing dollars, resources spent generating each sale and post-sales service and support; and customer value-related metrics such as the duration or longevity of that customer's relationship with your business, referral rate and share of wallet. Establishing a common set of customer metrics facilitates alignment and collaboration and provides both organizations with customer-oriented vocabulary and set of priorities.

\section{FROM SALES FUNNEL TO CUSTOMER BUYING PIPELINE}

We can transform a common tool, the sales funnel, used by many companies, as a way to improve alignment. The sales funnel is most 
often used by the sales organization to understand the flow of business opportunities. But the sales funnel has the opportunity to be so much more.

When developed properly, a sales funnel can serve as an important tool for improving marketing and sales alignment thereby improving both organizations' performance. Funnel management provides insight into which sales and marketing processes are effective and increase deal flow, as well as insight into how efficiently customer opportunities are moving through the stages of opportunity development.

The first step in using the sales funnel for these purposes is to integrate it with the customer buying process. As a result, the sales funnel ceases to be merely a tool for the sales team. It has actually evolved into what should be called the buying pipeline. Why does this matter? A sales funnel suggests two things. First, the term suggests that this process is something owned by sales and not necessarily a shared responsibility across the organization. Yet, Marketing plays a critical role in bringing potential buyers to the table. Marketing has the responsibility to identify, find and secure profitable customers - that is opportunities. Marketing also provides segmentation, customer targeting, positioning, product offers and messaging to differentiate the company. Therefore, both the marketing and sales functions within the organization are essential to building the buying process. Secondly, it suggests a transactional sales rather than a customer centricity approach to the buying decision process. Building a healthy sales funnel starts by understanding your customers' needs and their buying process. Before we can explore what to change, it helps to understand how the sales funnel is typically approached.

Today, most companies define the sales funnel similar to the illustration below. They use the metaphor of a funnel, something wide at the top and narrower at the bottom to describe and monitor the sales process. Marketing programs are designed, developed and executed for the purpose of bringing potential customers into the funnel. The width of the funnel suggests the number of potential customers at various stages in the selling process and the height represents the amount of time the average opportunity stays in the funnel before being converted to a customer.

The funnel is then divided into stages that are intended to represent the state of the opportunity. These stages are often labeled with names such as contact, suspect, lead, qualified lead, prospect, etc. Qualified leads are further divided based on how quickly the sales team thinks the conversion will occur and are often labeled A, B, C or some other denotation. There are two things someone can quickly notice about this typical approach. First, the funnel suggests that a lot more has to go in at the top of the funnel than what comes out at the bottom. That is, at the top of the funnel you have many people who you think might need your product or service, but to whom you have never spoken. At the bottom of the funnel, many sales and delivery steps later, you have people who have received delivery and paid for your product or service and have paid. People drop away at each stage of a long sales process:
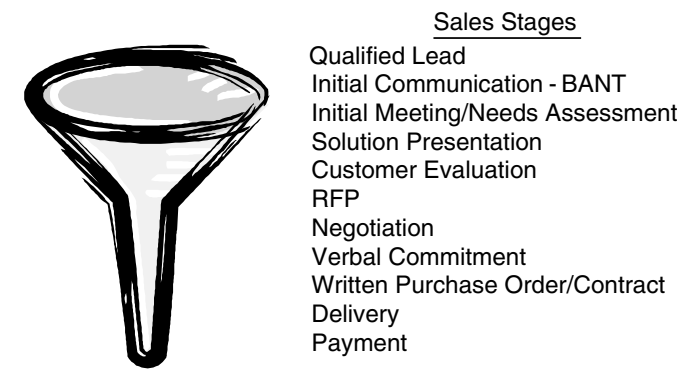

The Stages of the Typical Funnel

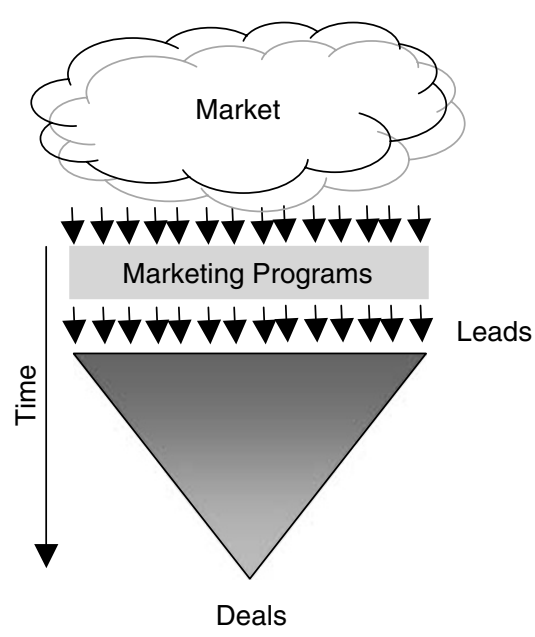


Perhaps the ideal shape of the funnel really is not a funnel at all. The ideal shape would actually look more like a pipe, where every opportunity that goes in at the front of the pipe would ultimately turn into a customer. While this is not realistic, transforming the funnel into a pipe does provide a different point of view. A pipe suggests that different marketing programs may be needed at different stages along the way and that segmentation, targeting and qualification are extremely important to reducing waste and customer acquisition costs.

The second thing that can be instantly noticed about the funnel is that it is based on stages defined by the company and not defined by the buying process. Developing a good pipeline requires understanding your customer's decisionmaking and buying process. Effective pipeline management is a reflection of your company's ability to not only identify the right opportunities and needs of your prospects, but to truly understand how they will go about making the purchase. Once you understand your customer's decision making and buying processes, you can develop a strategy for managing the opportunity at each stage in the pipeline.

By transforming the funnel into a pipeline you can begin the journey of marketing and sales alignment. Before developing your sales funnel, before defining your stages, before investing in a sales force automation tool or CRM system, map your ideal customer's buying process. We call this engineering the buying pipeline. This first step ensures that you understand why and how your customer makes a buying decision. It is possible you will have to create more than one buying process map. Different segments may buy differently and different products and services may have different purchasing processes.

Once you have mapped the process, the second step is to define each of the stages using incremental behavioral commitments. What is an incremental behavioral commitment? Let us use an everyday real-world example to illustrate the concept. When two people are both interested in finding a long-term relationship they begin the courting process. Certain demonstrated behaviors along the way indicate whether the relationship is progressing toward the ultimate behavior of saying "I do." For example, showing up for the first date, the first kiss, introducing each other to best friends, to the family, saying "I love you," actually proposing and so on are incremental behavioral commitments. This behavior demonstrates to both people that the relationship is going from initial contact to ultimate deal. The question we have for you is whether you have a clear understanding of the specific incremental behaviors your customers actually demonstrate that shows they are moving their commitment to the relationship forward. Until you do, you cannot create the buying pipeline and until the pipeline is created, you will not have a funnel focused on customer opportunities.

Once you have the behaviors defined you can take the third step and group the behaviors into stages. These stages will become the foundation for how you classify the status of each opportunity. Marketing can now develop tools appropriate for each stage enabling the sales organization to appropriately engage with the prospective customer.

At the end of this journey you will have a pipeline that looks like this:

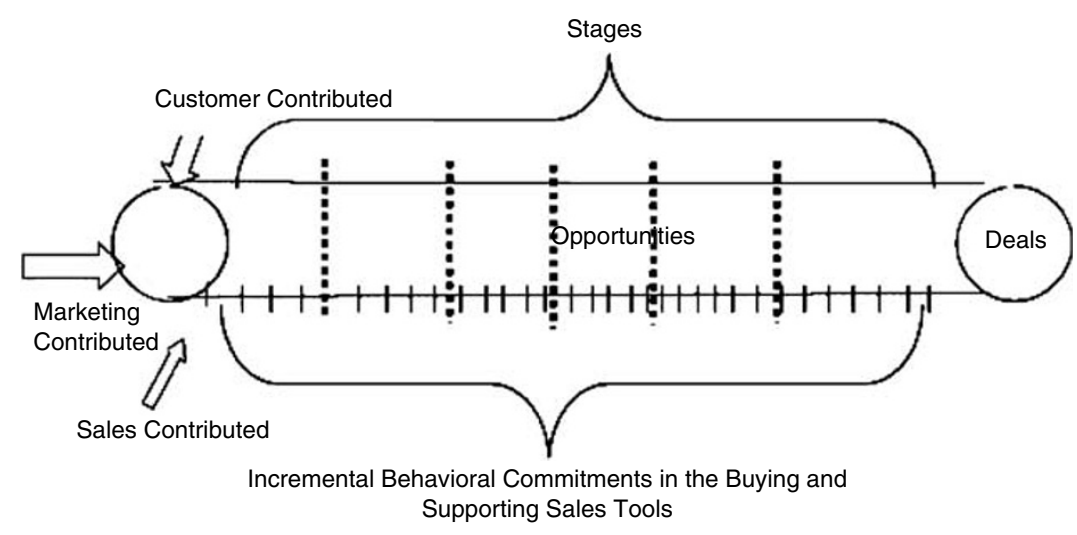


It is relatively easy to see how creating and properly using the buying pipeline serves as an excellent alignment and management tool. The idea behind pipeline management is that you can collect data throughout the process and continuously monitor multiple metrics, such as response-to-lead rate and response-to-sale rate. This data, over time, can then be used as a way to assess your marketing mix and evaluate the return on various marketing programs. The data can provide insight into which segments and mediums are performing as required and the types of prospects more likely to be qualified.

Pipeline management can also help identify where bottlenecks or gaps exist. For example, maybe there are too many contacts and the organization cannot process them quickly enough. Or there is a dearth of qualified leads indicating that the sales team would not be able to produce the needed number of deals. We can also use the pipeline and associated processes to compare our program's performance to industry standards. Pipeline management allows you to calibrate your marketing organization and synchronize marketing and sales efforts. It also allows you to take a more metric-based approach to opportunity and customer development enabling you to understand what is happening in the buying process and where to make adjustments. Pipeline management is really about managing opportunities. Opportunities represent customers that takes us back to the need for transforming the traditional sales funnel into an integrated customer buying pipeline.

\section{DOES ALIGNMENT MATTER?}

While no one can offer any guarantees, aligning marketing and sales makes good business sense and ultimately improves the bottom line. A study conducted by Aberdeen on sales effectiveness with more than 200 executives from the executive, sales, marketing and IT management functions found that companies that had strong collaboration between these two functions achieve higher sales effectiveness. By taking the two steps, From Transactional to Customer Centric and From Sales Funnel to Customer Buying Pipeline, your company can improve marketing and sales alignment in a relatively quick period of time and begin to reap the benefits of more revenue and profits. For many companies this additional boon in sales more than justifies making the effort. 